\title{
The patient within - psychopathology in the helping professions
}

\author{
Richard Tillett
}

Abstract Doctors, like other health professionals, show increased rates of psychological morbidity, including anxiety, depression, suicide, drug and alcohol misuse and professional exhaustion (burnout). This might be due in part to the pressures of clinical work, but might also reflect Malan's 'helping profession syndrome', in which an individual chooses, usually unconsciously, to work as a carer as a response to personal vulnerability, or 'the patient within'. This paper reviews the literature relating to the complex relationship that health professionals have with their work role, discusses the implications for the profession, and proposes areas of prophylactic or remedial action.

Like other health professionals, doctors show increased rates of psychiatric morbidity compared with the general population, and it is commonly believed that this occurs as a result of the pressures of clinical work. In 1997 an issue of APT explored the general topic of mental ill-health in doctors, focusing especially on phenomenology and treatment (see Box 1 for details on each paper).

\section{Box 1 Contents of $A P T$, vol. 3, issue 5, 1997}

Morgan, G., 'Editorial: Continuing Professional Development', p. 250.

Holmes, J., 'Editorial: Mental health of doctors', pp. 251-253.

Hale, R., 'How our patients make us ill', pp. 254-258.

Myers, M. F., 'Management of medical students' health problems', pp. 259-266.

Wilhelm, K. et al, 'Prevention and treatment of impairment in doctors', pp. 267-274.

Guthrie, E. \& Black, D., 'Psychiatric disorder, stress and burn-out', pp. 275-281.

Roberts, G. A., 'Prevention of burn-out', pp. 282-289.

Wrate, R. M. \& Baldwin, P. J., 'Health of tomorrow's doctors: obstacles to appropriate help-seeking', pp. 290-296.

Kesteven, S. et al, 'Health procedures of the General Medical Council', pp. 297-304.

Brandon, S. et al, 'Persuading the sick or impaired doctor to seek treatment', pp. 305-311.
There is evidence to suggest that many people choose to work in the helping professions because of personal psychopathology that renders them vulnerable to psychological stress - the 'helping profession syndrome'. Although increased staff morbidity probably results from the interaction of work pressures and personal psychopathology, it seems likely that many professionals unconsciously have a 'special relationship' with their work. This has implications for training and practice, both for doctors and for other members of multi-professional teams.

This paper reviews the literature relating to these topics and presents some personal reflections and recommendations for discussion. I have deliberately used a mixture of objective and subjective styles to reflect the ambivalence that is evident in our attitudes to our own potential morbidity (the 'patient within').

\section{Psychiatric morbidity in health professionals}

In general, health professionals have increased psychiatric morbidity, with high rates of anxiety, depression, suicide, alcohol and drug misuse (Payne \& Firth-Cozens, 1987; Heim, 1991; Guthrie \& Black, 1997). National Health Service (NHS) staff have higher rates of sickness absence than comparable staff groups in other sectors, and levels of staff turnover and wastage are very high. A study of 11600 NHS staff (Borrill et al, 1996; Wall et al, 1997) found an overall prevalence of psychological

Richard Tillett is a consultant psychiatrist/psychotherapist at Wonford House Hospital, Exeter EX2 5AF, UK and has a longstanding interest in the psychological problems of health professionals. 
morbidity of $27 \%$, compared with $18 \%$ in working people outside the NHS and $30 \%$ in the unemployed population. Female doctors and managers were found to be particularly at risk. A report published by the Nuffield Trust (Williams et al, 1998) presents a comprehensive review of the existing literature.

Doctors have been studied more often than other professional groups and have been shown to have increased rates of marital dysfunction, divorce, drug and alcohol problems and suicide (Vaillant et al, 1972; Charlton et al, 1993), with significantly higher rates in female doctors (Guthrie \& Black, 1997). High levels of psychiatric morbidity have been demonstrated at all stages of doctors' careers; in most studies using self-report measures, about a quarter of doctors are identified as being particularly vulnerable (Caplan, 1994; Firth-Cozens, 1995; Ramirez et al, 1996).

Other paramedical professions have been studied less intensively, but the evidence suggests even higher rates of general psychiatric morbidity in nurses than in doctors, with a general tendency for female workers to have higher morbidity than male workers (Borrill et al, 1996; Wall et al, 1997). Nurses have high rates of suicide and psychiatric outpatient referrals, and a study of psychiatric nurses at a special hospital revealed an increased level of psychiatric morbidity (Jones, 1987). Personal experience of conducting therapy groups for health professionals suggests that many have significant, though well-defended, levels of personal psychopathology (Tillett, 1986). For a summary of the signs of professional morbidity, see Box 2 .

\section{Professional attitudes and behaviours}

Examination of common attitudes and behaviours suggests that some health professionals have a complex and ambivalent relationship with their work role.

Doctors and other health care professionals are frequently criticised for being poor communicators

\section{Box 2 Evidence of professional morbidity}

NHS staff generally

Increased psychological morbidity

High sickness rates

Increased staff turnover and wastage

Doctors specifically

Increased psychological morbidity at all stages of career

Case prevalence $25 \%$ by self-report measures

Female doctors especially at risk and especially poor listeners. We have to balance the need to maintain a warm, humanitarian and empathic attitude against the need to be sufficiently defended and emotionally detached in order to remain objective. When we are struggling with our own feelings, we might find emotional contact with patients stressful and use 'business' as a convenient excuse for avoidance.

Doctors are notoriously difficult patients, prone to avoiding the patient role by denial and selfneglect, or by self-diagnosis and treatment (McKevitt et al, 1996; Forsythe et al, 1999). When doctors do seek help, they can have difficulties in accessing appropriate treatment (Wrate \& Baldwin, 1997). Personal clinical experience suggests that health professionals are ambivalent about the sick role and have particular difficulty in acknowledging psychological frailty, often presenting with displaced symptoms such as somatisation disorders, and behavioural disturbances such as alcohol or drug misuse.

Denial of sickness in colleagues is common throughout the health professions. A doctor who was admitted as a patient to her own hospital reported that, to her chagrin, she appeared to be invisible to friends and colleagues when wheeled around the hospital in a bed (Reynolds, 1996). A similar experience was described by an American endocrinologist with a disabling neurological illness:

'one day, while crossing the courtyard outside the emergency room, I fell. A long-time colleague was walking by. He turned and ours eyes met as I lay sprawled on the ground. He quickly averted his eyes, pretended not to see me, and continued walking. He never even broke his stride. I suppose he ignored the obvious need for help out of embarrassment and discomfort for I know him to be a compassionate and caring physician' (Rabin, 1982).

Health professionals often have difficulty in working collaboratively, whether with colleagues, other agencies or patients' relatives. Inter-professional tensions are common in the health services, and fragmentation of care provision often results (Department of Health, 1996). These difficulties often result from unrecognised personal or institutional rivalry and suggest a neurotic investment in the caring role.

Many health care staff show a very high level of professional commitment, working far beyond contracted hours and often neglecting personal welfare and family relationships as a result. 'Workaholics' are often highly valued and respected professionally, but are known to be at increased risk of professional exhaustion or burnout (Freudenberger, 1974; Edelwich \& Brodsky, 1980). 
Occasionally, health professionals commit serious offences against their patients, as in the cases of Beverley Allitt and Harold Shipman. Their actions contradict everything we believe about our role as caring professionals and suggest the possibility that professional motivation may often be more complex than a simple wish to help others.

\section{A special relationship?}

The increased psychiatric morbidity shown in health professionals, coupled with these characteristic patterns of behaviour, suggests that we may have a 'special relationship' with our work, or perhaps with the concept or experience of illness that underlies our career choice, predisposes us to an increased risk of psychological disorder and affects our behaviour in the workplace. It seems likely that this relationship results from the interaction of several factors, including the pressures of working in health care, underlying practitioner psychopathology and the effect of professional training.

\section{Work-related factors}

Many types of clinical work are inherently stressful (Payne \& Firth-Cozens, 1987). Areas where there is a high level of trauma or mortality (accident units, intensive care units, neonatal units) are perhaps the most obvious, but practitioners in all fields have to cope with heavy clinical workloads and everincreasing administrative demands. Concern has been expressed about the increase of threats and violence from patients and relatives (Health and Safety Executive, 1997). Staff in psychiatric admission units are exposed to high levels of behavioural disturbance, with an increased risk of personal assault (Kho et al, 1998), and those working in the community feel isolated and unsupported (Prosser et al, 1996). Apart from violence, various other categories of 'difficult' patients are recognised, including those with persistent symptoms unresponsive to treatment ('heartsink' patients), the litigious and the seductive. Institutional group dynamics at ward, team or unit level might also play a significant part (Hale, 1997), but are rarely examined.

Clinicians cite a variety of issues as stressors: workload pressures (and their effect on personal life), inadequate resources, inappropriate management techniques, constant reorganisation, role ambiguities and conflict, lack of career progression, inadequate support/supervision and lack of control over personal job circumstances (Williams et al, 1998). There have also been changes in cultural attitudes towards health professionals over the past 50 years, with an increase in patients' expectations and criticisms (including litigation) and a reduction in respect and compliance (Burke \& Richardson, 1996; Roberts, 1997; Thompson, 1998)

\section{Practitioner psychopathology}

A number of writers have explored the relationship between health professionals' psychopathology and their early life experiences. Much of the published work in this area relates to doctors or psychotherapists, but it seems likely that the underlying processes are more widely applicable.

The decision to study medicine is, like many choices, influenced by both conscious and unconscious factors. Conscious factors usually include academic success with an aptitude for scientific subjects, an interest in a professional career, a general wish to help people and (often) a medical family background. Unconscious components of the decision are clearly difficult to explore, but there is some evidence that doctors make their career choices in early adolescence or even before (Allen, 1988). Lief (1971) suggests that at least a third of medical students are motivated by unconscious neurotic drives and unresolved conflicts from childhood, and a number of writers have suggested that the choice of a medical career may serve as a defence against feelings of anxiety or impotence resulting from the experience of illness or death in family members (Feifel et al, 1967; Pfeiffer, 1983; Gabbard, 1985).

Similarly, the choice of a career in the helping professions may be an attempt to remedy early emotional neglect by taking an opportunity to give the care and attention to others that was never received as a child. Bowlby (1977) describes 'compulsive care giving' as a pattern of behaviour seen in people whose early attachments have been unsatisfactory: 'the typical childhood experience of such people is to have a [parent] who ... was unable to care for the child but instead welcomed being cared for ... the person who develops in this way has found that the only affectional bond available is the one in which he must always be the care giver, and that the only care he can ever receive is the care he gives himself'.

Malan (1979) refers to the 'helping profession syndrome', in which the professional 'compulsively gives to others what he would like to have for himself, which ... leads to a severe deficit in the emotional balance of payments' (p. 139). He speculates that such professionals perceive other people's needs as demands that they try to satisfy. If their attempts are unsuccessful, they render themselves vulnerable to depression. 
Johnson (1991) draws on self-psychology to suggest that deficiencies in parenting or the experience during childhood of illness in oneself or in family members might result in a narcissistic disturbance of personality that he characterises as 'fragile grandiosity'. This type of person is prone to emotional detachment and denial of personal vulnerability, and these personality traits might be reinforced by medical training and professional culture.

Several writers (e.g. Storr, 1979; Prodgers, 1991) have observed that psychotherapists commonly report disturbed attachments to their own parents, especially their mothers, and suggest that this might form a significant unconscious part of their interest in psychotherapy as a profession. In the same vein, Rycroft (1993) has suggested that some people become psychotherapists in order to ablate the memory of their own (unsatisfactory) parents, replacing this with an idealised projection of their own caring. Jacobs (1991) uses the notion of 'constructive vengeance' to suggest that many health professionals are motivated in their careers by a desire to put right perceived wrongs of the past, sublimating a wish for revenge into a conscious wish for reparation.

Zigmond (1984) introduces an interpersonal perspective, using the theory of transactional analysis as a model. He describes the symbiotic relationship between patient and doctor, in which the doctor has many parent-like qualities and the patient has correspondingly child-like ones. He observes that this relationship can be benign and productive, but that it can also become malignant. He goes on to suggest that factors that motivate us to become doctors might predispose us to the establishment of 'malignant symbiotic' relationships with our patients:

'When we deny powerful needs or impulses in ourselves we will either be intolerant or compulsively solicitous of these attributes in others. If it is the latter then we can professionalise this problem by working in one of the caring professions ... our needs may then be fulfilled in an illusory and vicarious way through a state of mutual dependence ... [S] uch dependence on our patients for our sense of power, self-esteem, worthiness and vicarious expression of locked up feeling is often not conscious.'

\section{The effect of training}

Whatever the underlying psychopathology, professional training will be a further formative experience. Zigmond (1984) suggests that medical training concentrates predominantly on 'masculine' aspects of the doctor's role, emphasising the importance of scientific, organisational and interventive skills at the expense of more 'feminine' attributes such as listening, caring and understanding. Bennet (1987) makes a similar point about the emphasis on science at the expense of humanities in the early stages of medical studies. He suggests that successful members of the medical profession tend to be authoritarian and convergent thinkers, and that these factors are emphasised by the selection and socialisation of medical students to produce what he calls the 'medical virtuoso', smartly dressed with white coat and stethoscope, knowledgeable, skilful and inviolable (p. 70). He suggests that this role is detrimental, both to patient care and to the mental health of the doctors concerned. Both writers refer to the ready collusion between health professionals and patients in the development of an idealised treatment relationship that is reinforced by training and cultural pressures.

\section{The patient within - a lifelong relationship}

It seems likely that the 'special relationship' referred to earlier, between health professionals and our work, results from the interplay of internal and external processes operating through our lives. Childhood difficulties, especially in the areas of attachment, care giving and illness, predispose to a neurotically driven need to care for others as a defensive reaction to feelings of anxiety, impotence or isolation. Our urge to care for others is, to some extent, driven by our unconscious identification with the patient role, based on projection of our own unmet emotional needs. We have an internal relationship with our own personal vulnerability (to be ill, frail, helpless, afraid, etc.), and our external professional behaviour is driven partly by this. Those with particularly disturbed childhood experiences are likely to have high levels of neurotic investment in the professional role and are especially at risk.

Clinical training is likely to encourage continuing denial, dissociation and projection of personal vulnerability, while professional competitiveness and the expectations of patients and carers will reinforce the 'virtuoso' role. Given the absorbing nature of clinical work and the high value traditionally attached to it, it is not surprising that we develop a symbiotic relationship with our patients and with our work. Over a professional lifetime, other influences will include the effects of career progression (or failure), personal illness and other life events, and psychological changes associated with ageing. 


\section{Professional exhaustion (burnout)}

To some extent, we all suffer from the helping profession syndrome - for each of us there is a 'patient within' and this can form a healthy basis for our professional motivation. It seems likely, however, that practitioners with more severe childhood disruption (and therefore higher levels of unconscious/neurotic drive to care for others) will form the most vulnerable group of health professionals. They might become intense, idealistic, single-minded, enthusiastic and committed practitioners who are already recognised as being at increased risk of burnout (Edelwich \& Brodsky, 1980). The factors contributing to this burnout are summarised in Box 3.

All clinicians cope with the stresses of work by using everyday psychological defence mechanisms such as humour and distraction. When things get more difficult, we fall back on more substantial defences such as avoidance, dissociation or conscious projection. Under extreme pressure, we revert to the use of primitive defences such as denial, splitting, unconscious projection and magical thinking. Real danger arises when we become isolated and unable (or unwilling) to compare our perceptions with those of our colleagues. The symptoms of professional exhaustion or burnout are comprehensively reviewed by Roberts (1997) and are summarised in Box 4.

The most serious dysfunction results from the sustained use of primitive defences in a situation of professional isolation. An extreme form of this is seen in professionals who covertly damage patients in their care. These people rarely show evidence of a

\section{Box 3 Factors contributing to professional morbidity}

Work-related

Intensive practice (the 'front line')

Perceived threat (e.g. violence, complaints)

Insecurity (poor support/management, reorganisation, etc.)

Personal

Early career choice

Exposure to illness/death in childhood

Emotional neglect/abuse

Dependent/narcissistic personality traits

Cultural

Socialisation during training

Symbiotic relationship with patients

Professional (peer) attitudes and pressures
Box 4 Symptoms of burnout (after Freudenberger, 1974; Maslach \& Jackson, 1986)

Emotional

Loss of humour (or excessive use of black humour)

Irritability/resentment/bitterness

Persistent mood of depression

Feelings of failure/guilt/blame

Apathy, low energy

Cognitive

Poor concentration

Rigidity/resistance to change

Suspicion/mistrust

Stereotyping

Objectification/distancing

Ruminations (of leaving, revenge, etc.)

Behavioural

Work avoidance (absenteeism, clock-watching, etc.)

Diminished personal contact with clients / colleagues

Stereotyped/inflexible behaviour

Habitual lateness

Acting out (alcohol/drugs/affairs/shoplifting, etc.)

Physical

Tiredness, lethargy

Sleep disorders

Increased minor illnesses (e.g. headache, backache)

clearly defined functional psychiatric disorder, but have major personality disturbances, often including an element of grandiosity, masked by the use of primitive, superficially effective psychological defences. Their actions, denied by themselves, are often overlooked or ignored by others who are reluctant to recognise the warning signs.

\section{Implications for the profession}

The increased psychological morbidity of health professionals is a matter of concern. In terms of clinical governance, we have a responsibility to ensure that staff are fit to do their jobs and that their performance is not unduly affected by personal problems, beliefs or attitudes. In terms of managing the workforce, we need to improve the recruitment, well-being, development and retention of staff. There are a number of implications for training and for clinical practice, which are summarised in Box 5 and discussed below. 
Box 5 Implications for training and practice

Realistic career information

Improved selection process

Early exploration of vulnerability

Training in self-management

Professional reviews (CPD) to include personal well-being

Career breaks

Mentoring schemes

Staff health as performance indicator

Supervision (clinical and personal)

Resolution of interpersonal tensions

Support groups

Personal 'maintenance' counselling or therapy

\section{Training}

We currently have little knowledge of how young people choose a career in health care, although we know that the choice is often made in childhood or early adolescence. The effects of parental and cultural influences are unclear. Career information for young people is fairly restricted and it seems likely that many make their choice with a limited understanding of what is involved. Further research is needed, but meanwhile we must ensure that realistic information is available to potential applicants.

Health care training is widely recognised as stressful for students: more careful examination of each student's potential vulnerability during the selection process would be helpful, although the results of psychological testing have so far been inconclusive. Given that a previous or family history of mental illness is a positive predictor of vulnerability, screening procedures should include this information. During training, students should be encouraged to recognise and discuss the link between their own life experiences and their career choice, emphasising that their personal vulnerabilities have both positive and negative potential in their careers. Students needing specific psychiatric or psychotherapeutic help should be able to access this readily, and the provision of such treatment should be without detriment to the individual's career.

After qualification, self-management skills should be included in postgraduate training programmes and appropriate support should be available on an informal basis. In psychiatry, this should be incorporated in the local training programme, and the trainees' handbook should contain simple advice and contact information for informal and professional support. Clinical training should include the particular problems of recognising and treating illness in colleagues and this topic should be included in professional examinations.

Consultants and other career grade staff are particularly at risk of institutionalisation and burnout. Programmes of continuing professional development and revalidation procedures for senior staff should include opportunities for personal reflection and self-review. Career breaks should be more widely available or even mandatory, as those most in need of them are those least likely to accept the idea. Mentoring schemes, such as the one for consultant psychiatrists in the South-West region, should be developed more widely.

\section{Clinical practice}

Most health professionals lead busy, stressful and demanding lives, almost always with significant workload pressure. All practitioners should be encouraged to develop their skills in time management and prioritisation, both to maximise their efficiency and to protect them against burnout. The job descriptions of managers should clearly include a responsibility for maintaining the well-being of their staff as well as supervising their clinical performance. Staff health should be established as a key performance indicator throughout the health service.

Postgraduate case meetings and audit activities are useful opportunities for mutual support and are often used to discuss work with colleagues informally. The inclusion of a session on stress management can offer the opportunity for clinicians of different disciplines and seniority to discuss practical solutions. Appropriate supervision should be included in the job description of all grades of staff (however senior) and can be provided on a hierarchical or peer basis; mentoring schemes are especially useful. Clinical governance and revalidation processes provide a vehicle for monitoring individual and collective performance, and should include a review of work stress.

Working in a multi-disciplinary team offers considerable opportunities for mutual support and peer supervision, and in a well-functioning team this will often occur on an informal basis. When team dynamics are less fluent (e.g. when hierarchical, inter-disciplinary or inter-agency tensions are evident), it might be helpful to consult with a specialist in interpersonal relationships (perhaps a systems or group analyst), or to arrange a regular staff support group with an external leader. Staff working in areas of especially high stress (e.g. intensive care units, oncology wards, acute psychiatric units) should be offered regular staff support groups led by an appropriately qualified person. Occupational health services should be 
readily available and should include psychiatric and psychotherapeutic expertise.

The role of personal therapy or counselling is unfortunately contentious, perhaps epitomising the ambivalent relationship we have with our own vulnerability. Most of us defer seeking personal help until a crisis forces us to do so - it is not yet fashionable, at least in public health services, to be in therapy. As professionals, we tend to think of therapy as a remedial treatment, overlooking its potential as a prophylactic or maintenance activity, analogous to servicing one's car. Therapy offers an opportunity for personal reflection away from the workplace, and also allows a review of the balance between work and other parts of one's personal life.

Many of these resources can be accessed, directly or indirectly, through local psychotherapy departments, most of which are happy to provide both consultative and direct clinical services.

\section{Conclusions}

The effective functioning of any health service requires that its staff are maintained in good health themselves. It is clear that health professionals have an increased incidence of psychological morbidity, and there is anecdotal evidence suggesting that this affects their clinical practice. The mental health of staff and patients alike is affected by antecedent life experiences and contemporary work pressures. Professionals whose career choice and clinical practice are motivated significantly by unrecognised personal psychopathology are likely to have an increased risk of work-related stress. The maintenance of staff health must be seen as the joint responsibility of management and of staff themselves at all stages of professional development, from selection and training onwards. Remedial action can be taken at a practical level but we need to be aware of the complex psychological processes that lie beneath the surface of the problem.

\section{References}

Allen, I. (1988) Doctors and their Careers. London: Policy Studies Institute.

*Bennet, G. (1987) The Wound and the Doctor: Healing Technology and Power in Modern Medicine. London: Secker \& Warburg.

*Borril, C. S., Wall, M. A., West, G. E., et al (1996) Mental Health of the Workforce in NHS Trusts. Leeds: Institute of Work Psychology, University of Sheffield \& Department of Psychology, University of Leeds.

Bowlby, J. (1977) The making and breaking of affectional bonds. British Journal of Psychiatry, 130, 201-210.

Burke, R. \& Richardson, A. (1996) Stress burnout and health. In Handbook of Stress, Medicine and Health (ed. C. Cooper). London: CRC Press.

Caplan, R. (1994) Stress, anxiety and depression in hospital consultants, general practitioners and senior health service managers. BMJ, 309, 1261-1263.
Charlton, J., Kelly, S., Dunnell, K., et al (1993) Suicide deaths in England and Wales: trends in factors associated with suicide deaths. Population Trends, 71, 34-42.

Department of Health (1996) Building Bridges: A Guide to Arrangements for Interagency Working for the Care and Protection of Severely Mentally Ill People. London: HMSO.

*Edelwich, J. \& Brodsky, A. (1980) Burn-out: Stages of Disillusionment in the Helping Professions. New York: Human Sciences Press.

Feifel, H., Hanson, S., Jones, R., et al (1967) Physicians consider death. Proceedings of 75 th Annual Convention of the American Psychological Association. Washington, DC: American Psychological Association.

Firth-Cozens, J. (1995) Stress in Doctors: A Longitudinal Study. Leeds: University of Leeds.

Forsythe, M., Calnan, M. \& Wall, B. (1999) Doctors as patients: postal survey examining consultants' and general practitioners' adherence to guidelines. BMJ, 319, 605-608.

Freudenberger, H. (1974) Staff burnout. Journal of Social Issues, 30, 159-166.

Gabbard, G. (1985) The role of compulsiveness in the normal physician. Journal of the American Association, 254, 29262929.

*Guthrie, E. \& Black, D. (1997) Psychiatric disorder, stress and burnout. Advances in Psychiatric Treatment, 3, 275-281.

Hale, R. (1997) How our patients make us ill. Advances in Psychiatric Treatment, 3, 254-258.

Health and Safety Executive (1997) Violence and Aggression to Staff in the Health Service - Guidance on Assessment and Management. London: Health \& Safety Executive.

Heim, E. (1991) Job stressors and coping in health professions. Psychotherapy and Psychosomatics, 55, 90-99.

Jacobs, M. (1991) The therapist's revenge: the law of talion as a motive for caring. Interdisciplinary Journal of Pastoral Studies, 105, 2-11.

*Johnson, W. (1991) Predisposition to emotional distress and psychiatric illness amongst doctors: the role of conscious and experiential factors. British Journal of Medical Psychology, 64, 317-329.

Jones, J. (1987) Stress in psychiatric nursing. In Stress in Health Professionals (eds R. Payne \& J. Firth-Cozens), pp.189-200. Chichester: John Wiley \& Sons.

Kho, K., Sensky, T., Mortimer, A., et al (1998) Prospective study into factors associated with aggressive incidents in psychiatric acute admission wards. British Journal of Psychiatry, 172, 38-43.

Lief, H. (1971) Personality characteristics of medical students. In Psychosocial Aspects of Medical Training (eds. R. Coombs \& C. Vincent). Springfield, IL, USA: Thomas.

Malan, D. (1979) Individual Psychotherapy and the Science of Psychodynamics. London: Butterworth

Maslach, C. \& Jackson, S. (1986) The Maslach Burn-out Inventory Manual (2nd edn). Palo Alto, CA: Consulting Psychologists' Press.

McKevitt, C., Morgan, M., Simpson, J., et al (1996) Doctors' Health and Need for Services. London: Nuffield Provincial Hospitals Trust.

*Payne, R. \& Firth-Cozens, J. (1987) Stress in Health Professionals. Chichester: John Wiley \& Sons.

Pfeiffer, R. (1983) Early adult development in the medical student. Mayo Clinic Proceedings, 58, 127-134.

Prodgers, A. (1991) On hating the patient. British Journal of Psychotherapy, 8, 144-154.

Prosser, D., Johnson, S., Kuipers, E., et al (1996) Mental health, 'burnout' and job satisfaction among hospital and community-based mental health staff. British Journal of Psychiatry, 169, 334-337.

Rabin, D. (1982) Compounding the ordeal of ALS: isolation from my fellow physicians. New England Journal of Medicine, 307, 506-509.

Ramirez, A., Graham, J., Richards, M. A., et al (1996) Mental health of hospital consultants: the effects of stress and satisfaction at work. Lancet, 347, 724-728.

Reynolds, F. (1996) Are hospital patients fellow human beings? BMJ, 312, 982-983. 
Roberts, G. (1997) Prevention of burnout. Advances in Psychiatric Treatment, 3, 282-289.

Rycroft, C. (1993) Why analysts need their patients' transferences. British Journal of Psychotherapy, 10, 83-87.

Storr, A. (1979) The Art of Psychotherapy. London: Secker \& Warburg

Thompson, C. (1998) The mental state we are in: morale and psychiatry. Psychiatric Bulletin, 22, 405-409.

Tillett, R. (1986) Providing therapy for therapists. Bulletin of The Royal College of Psychiatrists, 10, 27-28.

Vaillant, G. E., Sobowale, N. C. \& McArthur, C. (1972) Some psychological vulnerabilities of physicians. New England Journal of Medicine, 287, 372-375.

Wall, T. D., Bolden, R. I., Borrill, C. S., et al (1997) Minor psychiatric disorder in NHS Trust staff: Occupational and gender differences. British Journal of Psychiatry, 171, 519523

*Williams, S., Michie, S., Pattani, S., et al (1998) Improving the Health of the NHS Workforce. London: Nuffield Trust.

Wrate, R. \& Baldwin, P. (1997) Health of tomorrow's doctors: obstacles to appropriate help-seeking. Advances in Psychiatric Treatment, 3, 290-296.

*Zigmond, D. (1984) Physician heal thyself: the paradox of the wounded healer. British Journal of Holistic Medicine, 1, $63-71$

* denotes items of particular interest.

\section{Multiple choice questions}

1 In terms of NHS staff morbidity:

a overall, rates are lower than for the general population

b female workers have high rates

c doctors have the highest rates

d rates are equivalent to those for unemployed people

e managers have low rates.

2 Compared with the general population, doctors have:

a a low suicide rate

b low rates of marital dysfunction

c high rates of alcohol misuse

$\mathrm{d}$ reduced rate of neurotic disorder

e low morbidity in female practitioners.
3 Common work stressors in health care include:

a high workload

b staff group coherence

c role ambiguity

d consistent organisational structure

e poor control over personal work circumstances.

4 The following may contribute to Malan's 'helping profession' syndrome:

a childhood experience of emotional neglect

b early career choice

c denial of patients' needs

d projection of practitioners's needs onto patients

e patient autonomy.

5 Symptoms of professional burn out include:

a decreased contact with colleagues

b increased work commitment

c help-seeking behaviour

d increased productivity

e stereotypic thinking. 